\title{
RESENHA DAS INVESTIGAÇÕES SOBRE O ICTIOPLÂNCTON DO ESTUÁRIO DA LAGOA DOS PATOS, BRASIL*
}

\author{
GRACIELA WEISS E J.A. FEIJÓ DE SOUZA \\ Base Oceanográfica Atlântica - Fundação Universidade do Rio Grande \\ Rio Grande, RS, Brasil
}

\section{SYNOPSIS}

A short review on estuarine ichthyoplankton identification, description and growth is given. The need for qualitative, quantitative. horizontal and temporal distributions related to environmental factors, period and kind of spawning and fecundity of different species are discussed. Results of studies on Micropogonias furnieri, Brevoortia pectinata, Lycengraulis olidus, Achirus garmani and other suggest the necessity to sample fish larvae and juveniles at mid water, bottom and at the margin of the estuary. Further more, it would be of interest to extent and periodically survey the study area to the adjacent coastal waters, and the fresh water part of the Lagoon as well as the channels and tributaries.

\section{In trodução}

Tem-se por objetivo expor e comentar, brevemente, as investigações, até aqui realizadas, sobre o ictioplâncton do estuário da Lagoa dos Patos. Os estudos começaram em dezembro de 1975 , com o primeiro cruzeiro do Projeto Lagoa. Atualmente conta-se com 24 cruzeiros que cobrem dois ciclos anuais de investigações. Cada cruzeiro, principal fonte de dados para as investigações, foi divulgado pela Série Relatórios, FURG-BOA, Rio Grande.

Uma das limitações foi a impossibilidade de amostrar em áreas pouco profundas e nas águas costeiras adjacentes. Outra, a escassa bibliografia sobre o ictioplâncton da região.

Dependendo das condições reinantes, o estuário pode ser enquadrado em qualquer dos quatro tipos de classificação de Pritchard. Registram-se penetraçōes importantes de água salgada nos meses de verão e outono, devido ao efeito combinado de ventos do quadrante sul e pequeno índice pluviométrico. Os valores de alinidade superficial múnima e máxima foram: em primavera 0,28 e $28,90 \%$ o ; em verão, 0,20 e $32,80 \%$ oo; em outono, 2,22 e $30,20 \%$ e em inverno, 0,14 e $11,50 \%$. Além das variaçōes sazonais de temperatura, notam-se gradientes longitudinais, onde os menores valores ocorrem nas ăteas próximas a desembocadura, associados a presença de águas de origem marinha. Os valores de temperatura superfiçial múnima e máxima foram: em primavera. 15,40 e $21,20^{\circ} \mathrm{C}$; em verão, 21,60 e $28,60^{\circ} \mathrm{C}$; em outono, 14,10 e $23,60^{\circ} \mathrm{C}$ e em inverno, 11,20 e $17,70^{\circ} \mathrm{C}$. (Moller Jr., no prelo).

Identificou-se, a nível de espécie: Brevoortia pectinata, Anchoa marinii, Engraulis anchoita, Lycengraulis olidus, Parapime lodus valenciennis, Hyporhamphus kronei, Cynoscium striatús, Macrodon ancylodun, Menticirrhus amencamus, Micropogonias furnieri, Paralonchurus brasiliensis, Umbrina canosai, Trichiurus lepturus e Achírus garmani. A nível de gênero: Gobiesox sp, Syn. gnathus sp, Mugil sp e Paralichthys sp. E a nível de famnlia: Atherinidae, Carangida e Gobiidae.

\section{Investigaçōes conchuídas}

L. olidus e $B$. pectinata foram descritas desde a etapa de ovo até juvenil (40 e $21 \mathrm{~mm}$ respectivamente). Descreveu-se a ossificação de $L$. olidus aos 13 e $40 \mathrm{~mm}$ e de $B$. pectinata aos 13 e $21 \mathrm{~mm}$. Nas descrições usou-se a técnica de coloração por alizarina. Para o crescimento, utilizaram-se 741 exemplares (4-180 $\mathrm{mm})$ de $L$. olidus e $192(5-120 \mathrm{~mm})$ de $B$, pectinata. Tomaram-se as medidas de comprimento total, altura do corpo e distâncias preanal, predorsal e preventral. Observou-se o crescimento alométrico das duas espécies, sendo que, para a primeira, a metamorfose termina aos $40 \mathrm{~mm}$ e para a segunda aos $20 \mathrm{~mm}$. (Weiss \& Krug, 1977).

Fez-se um estudo morfológico comparativo preliminar entre $A$. marinii, $L$. olidus e $E$. anchoita. Os exemplares $(20,30$ e $50 \mathrm{~mm}$ ), provêm da costa da Argentina, do Uruguai, do sul do Brasil e do estuário da Lagoa dos Patos. Usou-se a técnica de coloraçâo por alizarina. Como elementos de comparação utilizaram-se: comprimento da cabeçà. altura do corpo, distâncias predorsal. preventral e preanal, arco branquial, premaxila, maxila, mandíbula, número de dentes, opérculo, arco hióideo, raios branquiostegais, aleta caudal, coluna vertebral e posicionamento das aletas. $\mathrm{O}$ processo de metamorfose completa-se em $A$. marinii aos $30-32 \mathrm{~mm}$, em $L$. olidus aos 40-41 mm e em $E$. anchoita aos $43-44 \mathrm{~mm}$. Como elementos diagnósticos principais tem-se o número de vértebras (respectivamente, 42,45 e 46 ), posicionamento das aletas, forma da cabeça e grau de ossificação (Weiss \& Souza, 1977).

Descreveram-se oṿos e larvas de $M$. furmieri até juvenil (40 $\mathrm{mm}$ ), com material obtido nos 19 primeuros cruzeiros do Projeto Lagoa. Foi descrito o processo de ossificação (coloração por alizarina) em postlarvas de 7 a $16 \mathrm{~mm}$, ponto onde o processo se completa. Para o estudo do crescimento tomaram-se medidas de 176 exemplares de 6 a $50 \mathrm{~mm}$. Apresentaram-se as seguintes relaçōes: comprimento standard/cabeça; comprimento standard/altura; com primento standard/distância predorsal; comprimento standard/distância preanal; altura/cabeça e focinho/cabeça; observando-se uma população homogênea. A desova foi mais intensa de novembro a janerro. As maiores concentrações de ovos foram encontradas em águas com altas salinidades (Weiss, no prelo).

Descreveu-se o desenvolvimento embrionário e larval de A. garmani. Obseryou-se sua distribuicão auantitativa, espacial e temporal. As distribuições de freqüencia porcentual dos adultos mostraram-se sempre unimodais (Proj. Lagoa, 10 cruz., 1620 exemplares). Os modos situaram-se sempre nas categorias centrais, sem mostrar deslocamento durante o ciclo anual. A relação comprimento/peso obtida foi: $\mathrm{P}(\mathrm{g})=0,02133[\mathrm{CT}(\mathrm{cm})]^{2,9678}$, com um coeficiente de correlação, $r=0,99678$. O valor mensal médio do fator de condição apresentou dois máximos (nov.77 e mar.78) e um (jul.77). Seu período de desova (através do material planctônico) estende-se desde outubro até abril. Sua intensidade máxima ocorre em janeiro. A mediçāo de 4640 ovocitos intraovários (11 fêmeas) indicou duas, ou mais, desovas sucessivas. Para a fecundidade, usou-se o método gravimétrico. Utilizaram-se 58 exemplares coletados em dez.76 e 17 em mar.77. Aos $105 \mathrm{~mm}$ de comprimento, a fecundidade real média para os desovantes de dezembro foi de 8210 e para os de março 5809. Essa diferença foi considerada significante estatisticamente (Weiis \& Haimovici, no prelo).

A partir de 508 amostras obtidas nos primeiros 19 cruzeiros do Projeto Lagoa, abrangendo o período entre dez./75 e jun /77 fez-se um estudo do ictioplâncton do estuário da Lagoa dos Patos. Pela distribuição temporal esquematizouse quatro grupos de espécies, desde o ponto de vista de suas presenças no estuário. Quanto a distribuição espacial, os ovos ocupam a zona do estuário, ultrapassando a Ilha da Sarangonha em algumas ocasiōes, enquanto as larvas ocupam toda a área estuarial, especialmente a zona norte. As larvas de $B$. pectinata e $L$. olidus e os ovos de $M$. furnieri apresentaram as maiores áreas de distribuiçãô. Em termos quantitativos, a média total de ovos foi de $735 / 100 \mathrm{~m}^{3}$ e a das larvas $31 / 100 \mathrm{~m}^{3}$ Os ovos e larvas apresentaram picos de maior abundância em primavera e verão. Predominaram os ovos de $M$. furnieri e as larvas de $L$. olidus e $B$. pectinata. As larvas mostraram diferentes coexistências, tendo-se as espécies $L$. olidus e $B$. pectinata coexistindo em grande escala e $L$. olidus $\operatorname{com} M$. furnieri em pequena escala. A salinidade foi o fator de maior influência na ocorrência de ovos e larvas no estuário. A maioria das espécies desovou em águas marinhas costeiras ou, excepcionalmente, no canal de acesso, quando condicionadas por grandes penetraçōes de águas marinha. Os ovos de $M$. furnieri apresentaram a maior eurihalinidade e os de $T$, lepturus a menor. (Weiss \& Souza, no prelo).

\section{Investigaçōes em andamento}

Com o objetivo de estudar a distribuição vertical e a penetração de ovos e larvas no estuário, foram coletadas amostras simultâneas em dois pontos no canal de acesso, durante um ciclo anual (Programa RELAR, nov.77 - out.77). As amostras foram tomadas com intervalo de sete dias, em três profundidades diferentes para cada ponto, também simultâneas, com tempo de coleta de $12 \mathrm{~h}$, co- 
brindo um período noturno e outro diumo, durante 4 a 6 semanas consecutivas para cada estação do ano. As coletas totalizaram 234 amostras, as quais encontram-se em final de processamento. (Pesq. responsáveis: G. Weiss e J.A. Feijó de Souza).

A partir do material coletado pelo Programa RELAR e Projeto Lagoa, iniciow-se um estudo descritivo e comparativo dos sienídeos identificados (larvas e juvenis). (Pesq. responsável: G. Weiss)

Com material proveniente do Projeto Lagoa e Programa RELAR, encontra-se em andamento um estudo sobre a alimentação de larvas de $M$. furnieri. Observou-se o espectro alimentar de 200 exemplares $(2-30 \mathrm{~mm})$, relacionando-os com temperatura, salınidade e alguns aspectos biometricos dos exemplares. Como resultados preliminares tem-se que as larvas foram capazes de iniciar sua alimentação ativa antes da reabsorçāo total da gota de óleo. Em janeiro, as mesmas, tenderam a reabsorver a gota e tornarem-se ativas com menor comprimento que em novembro. Os copépodes apareceram com o item de maior constâncıa nos conteúdos. (Pesq. responsável: J.A. Feijó de Souza).

Com material proveniente do Projeto Lagoa, foram tomadas medidas como, diâmetro total, vitelo, gota de óleo e espaço perivitelinico de ovos (4.000) de $M$. furnieri. Tem-se por objetivo analisar as variaçōes desses parâmetros em relação a época do ano, salinidade e temperatura. (Pesq. responsável: G. Weiss).

Encontra-se em estudo a fecundidade e o tipo de desova de $B$ pectinata. Utilizaram-se 80 exemplares coletados entre ago.-dez./ 77 pela frota comercial em pesca costeira. Através da medição de 3.000 ovócitos intraováricos de 11 fèmeas, em diferentes graus de maturação, observaram-se características próprias de um desovante parcial. $O$ estudo referente a fecundidade encontra-se ainda em ela boração. (Pesq. responsáveis: M. Haimovici e G. Weiss).

\section{Discussão}

Tratando-se de um ecossistema com características de estuário, acredita-se que é mais importante in tensificar os estudos no sentido do comportamento global do ambiente, que conhecer as particularidades de cada especie. Pois a reduzida area, com suas intensas trocas ambientais, afeta as populações como um todo. Torna-se necessário assim, estudar mais intensamente os processos de entrada, saída e distribuição do ictioplâncton e como tais processos são condicionados.

Nesse sentido conta-se com dados de dois anos de levantamento de distribuição horizontal, temporal, qualitativa e quantitativa do ictioplâncton superficial em diferentes condições ambientais. Paralelamente, tem-se a coleta de amostras estratificadas durante um ciclo anual (Programa RELAR), com as quais serão obtidas informaçōes sobre a distribuição vertical e correlações com as vazantes e enchentes do estuário.
Observa-se então, a necessidade de programar, a curto prazo, coletas capazes de capturar larvas e juvenis em meia água, fundo e margens da Lagoa. Por outro lado, amostrar as aguas mais internas, canais e afluentes da mesma, com a finalidade de complementar as informações sobre distribuição e penetração das diferentes especies. Da mesma forma, investigar as águas costeiras adjacentes, quanto a época e intensidade de desova das diferentes espécies que utilizam o estuário como área de criação. Visto que, por exemplo, observou-se a presença contínua de pequenas larvas de $L$. olidus e $B$. pectinata no transcurso dos dois ciclos anuais, enquanto seus ovos não foram detectados nas coletas de inverno. Busca-se assim, saber se as grandes vazantes, características do inverno impedem a penetração dos ovos ou se não há desova de inverno. Fato semelhante ocorre $\operatorname{com} M$. furnieri.

Considera-se, também, de grande importância, manter as zonas propostas, constantemente monitoriadas, não só a nível de icitioplâncton, mas de forma integrada, com outros ramos de pesquisa.

Finalmente, é necessário efetuar estudos experimentais em relação ao desenvolvimento, fisiologia, comportamento, alimentação e mortalidade das espécies, os quais daräo, em conjunto, as bases necessárias para uma melhbr interpretação biológica do estuário.

\section{Bibliografia}

MOLLER Jr., O.O. Sobre a distribuição e variação de alguns parâmetros físicos da Lagoa dos Patos. Atlântica, Rio Grande. (no prelo).

WEISS, G. Desova, identificação e descrição dơs primeiros estágios de vida da corvina (Micropogonias furnieri) do estuário da Lagoa dos Patos, Brasil. Atlântica, Rio Grande, 2(3). (no prelo).

\& HAIMOVICI, M. Desova, fecundidade e desenvolvimento embrionário e larval de Achirus garmani (Soleidae) do estuário da Lagoa dos Patos, Brasil. Attântica, Rio Grande. (no prelo).

_. . - \& KRUG, L.C. 1977. Caracteristicas do desenvolvimento e metamorfose de Lycengraulis olidus (Engraulidae) e Brevoortia pectinata (Clupeidae) no estuário da Lagoa dos Patos, Brasil. Atlântica, Rio Grande. 2 (1) : 83-117.

- \& SOUZA, J.A.F. de 1977. Estudo comparativo preliminar de postlatras e juvenis das três espécies de Engraulidae da costa sul do Brasil, Uruguai e Argentina. Atlântica, Rio Grande, $2(1): 1-20$ - Estudo do ictioplancton do estuário da Lagoa dos Patos, RS, Brasil. Atlântica, Rio Grande, 2(3). (no prelo) 